\title{
GaN evaporation and enhanced diffusion of Ar during high-temperature ion implantation
}

\author{
I. Usova) and N. Parikh \\ Curriculum in Applied and Materials Science, University of North Carolina at Chapel Hill, Chapel Hill, \\ North Carolina 27599-3287
}

Y. Kudriavtsev and R. Asomoza

Departmen Ingeneria Electrica-SEES, CINVESTAV-IPN, Mexico D.F., 07300, Mexico

Z. Reitmeier and R. Davis

Department of Materials Science and Engineering, North Carolina State University, Raleigh, North Carolina 27695-7919

(Received 18 November 2002; accepted 5 February 2003)

\begin{abstract}
GaN films were implanted with $150 \mathrm{keV} \mathrm{Ar}^{+}$at temperatures up to $1100{ }^{\circ} \mathrm{C}$ to a dose of 3 $\times 10^{15} \mathrm{~cm}^{-2}$. Concentration profiles of Ar were measured by secondary ion mass spectroscopy and depth distributions of ion-induced damage were estimated from Rutherford backscattering/ channeling spectra. No redistribution of Ar atoms was detected up to $700{ }^{\circ} \mathrm{C}$. At $1000^{\circ} \mathrm{C}$ a deep penetrating diffusion tail and a shift of the Ar peak to the surface were observed. At temperatures higher than $800{ }^{\circ} \mathrm{C}$ shift of the damage peak to the surface was also observed. We attributed the shift of the Ar peak and the damage peaks to evaporation of thin layer of $\mathrm{GaN}$ during high-temperature implantation and estimated its temperature dependence. (C) 2003 American Institute of Physics.
\end{abstract}

[DOI: $10.1063 / 1.1564271]$

\section{INTRODUCTION}

Ionization energy of dopants in $\mathrm{GaN}$ are relatively large and consequently high doses of dopants have to be introduced for creating low resistive layers. When the doping is carried out by ion implantation production of heavily damaged or amorphous layers may result from high-dose implantations. Studies of GaN implanted at liquid nitrogen and room (RT) temperatures demonstrated that such damage could not be completely removed by the subsequent annealing. ${ }^{1,2}$

High-temperature ion implantation is a promising doping technique for $\mathrm{GaN}$ because it allows avoiding amorphization during high-dose implantation. However, in this case, sputtering, thermal decomposition of a substrate and radiation enhanced diffusion of implanted dopants may take place. These effects may have a detrimental effect on characteristics of $\mathrm{GaN}$ electronic devices fabricated by ion implantation and have to be taken into account.

\section{EXPERIMENT}

The GaN layers were grown on (0001) 6H-SiC substrates by metalorganic vapor phase epitaxy. The samples were implanted with $3 \times 10^{15} \mathrm{~cm}^{-2} \mathrm{Ar}^{+}$ions at $150 \mathrm{keV}$. The implantations were done at two dose rates of 0.45 and 4.5 $\mu \mathrm{A} / \mathrm{cm}^{2}$, which further will be referred to as low and high dose rate, respectively. For implantations at elevated temperatures, samples were mounted onto a graphite strip, which was heated up to $1000^{\circ} \mathrm{C}$ by passing an ac current. In the

a) Present address: Los Alamos National Laboratory, MST-STC, Los Alamos, NM 87545; electronic mail: iusov@lanl.gov samples implanted at the high dose rate additional temperature rise of about $100{ }^{\circ} \mathrm{C}$ was observed. The concentration profiles of Ar were obtained by secondary ion mass spectroscopy (SIMS). The ion-induced damage was determined by Rutherford backscattering spectroscopy in the channeling mode (RBS/C) with $2.3 \mathrm{MeV} \mathrm{He}^{+}$ions aligned along $\langle 0001\rangle$ axis of $\mathrm{GaN}$ samples. The glancing angle geometry with scattering angle of $108^{\circ}$ utilized in the RBS/C measurements allowed to achieve depth resolution of the order of $10 \mathrm{~nm}$.

\section{RESULTS AND DISCUSSION}

Figure 1 shows SIMS profiles of Ar implanted in $\mathrm{GaN}$ at the low dose rate and temperatures $\left(T_{\mathrm{imp}}\right)$ of RT and $1000^{\circ} \mathrm{C}$. Implantation at RT, 400 , and $700{ }^{\circ} \mathrm{C}$ did not cause any noticeable changes in Ar distributions within the SIMS measurements depth resolution of $\sim 5 \mathrm{~nm}$. These profiles were fitted by a Gauss function with a projected range $\left(R_{p}\right)$ of $100.3 \pm 0.6 \mathrm{~nm}$ and a standard deviation $\left(d R_{p}\right)$ of 42.7 $\pm 1.1 \mathrm{~nm}$.

Implantation at $T_{\mathrm{imp}}=1000^{\circ} \mathrm{C}$ dramatically altered the concentration profile of Ar. In the region around the $R_{p}$ up to the depth of about $230 \mathrm{~nm}$ the Ar distribution retained the Gaussian shape but became slightly wider $\left(d R_{p}=46.1\right.$ $\pm 1.1 \mathrm{~nm}$ ) and its maximum shifted to the sample surface and was located at $79.8 \pm 0.6 \mathrm{~nm}$. The concentration of Ar in the maximum slightly decreased due to the peak widening. At the depth greater than $230 \mathrm{~nm}$ the concentration profile had a sharp kink and a deep penetrating diffusion tail. Such considerable motion of Ar atoms can be attributed to radiation enhanced diffusion because diffusion coefficients of dopants implanted into GaN and subsequently annealed are usually very low. ${ }^{3}$ The diffusion coefficient of $\mathrm{Ar}$ in the tail 


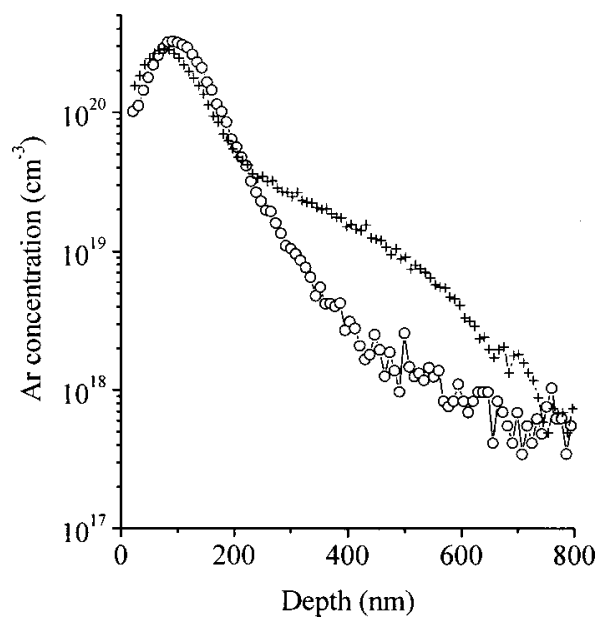

FIG. 1. SIMS profiles of $150 \mathrm{keV} \mathrm{Ar}^{+}$implanted into $\mathrm{GaN}$ to the dose of $3 \times 10^{15} \mathrm{~cm}^{-2}$ at RT (circles) and $1000{ }^{\circ} \mathrm{C}$ (crosses).

region was determined by fitting the concentration profile with the analytical solution of the diffusion equation derived in Ref. 4. The effective diffusion coefficient at $T_{\mathrm{imp}}$ $=1000{ }^{\circ} \mathrm{C}$ was estimated to be $(4.4 \pm 0.5) \times 10^{-13} \mathrm{~cm}^{2} / \mathrm{s}$.

The widening of the profile in the region around the $R_{p}$ can also be attributed to the diffusion process with significantly lower diffusion coefficient than in the tail region. However, the facts that the peak maximum shifted to the surface and the shape of the peak did not change most likely indicate that evaporation of thin layer of $\mathrm{GaN}$ film during implantation took place. According to the equation describing the modification of the implantation profile due to sputtering ${ }^{5}$ the changes in Ar profile at $T_{\text {imp }}=1000^{\circ} \mathrm{C}$ correspond to $\sim 40 \mathrm{~nm}$ of the removed layer thickness. Since influence of the diffusion and the surface erosion on the Ar profile shape is difficult to separate the location of the peak maximum can be taken as a measure of the evaporated layer thickness. In doing so, one should take into account that the peak shift corresponds to the half of the thickness of the removed layer.

Figure 2 shows depth distributions of damage extracted

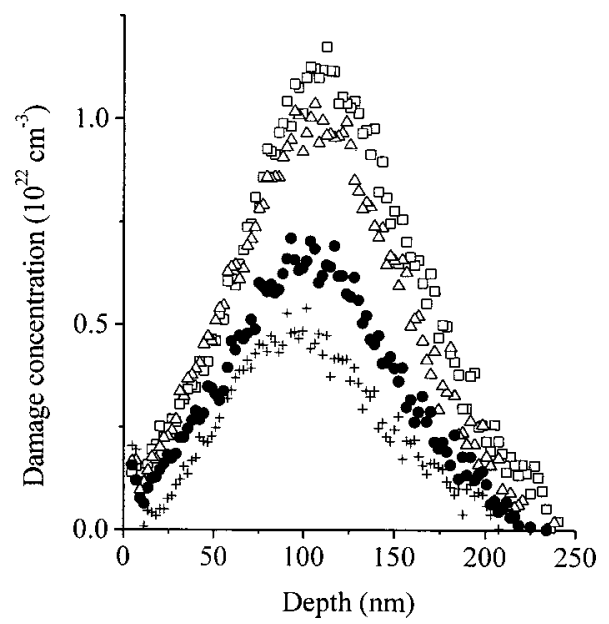

FIG. 2. Depth distribution of damage in GaN implanted with $\mathrm{Ar}^{+}$at the low dose rate and different temperatures: 700 (squares), 800 (triangles), 900 (circles), and $1000^{\circ} \mathrm{C}$ (crosses).

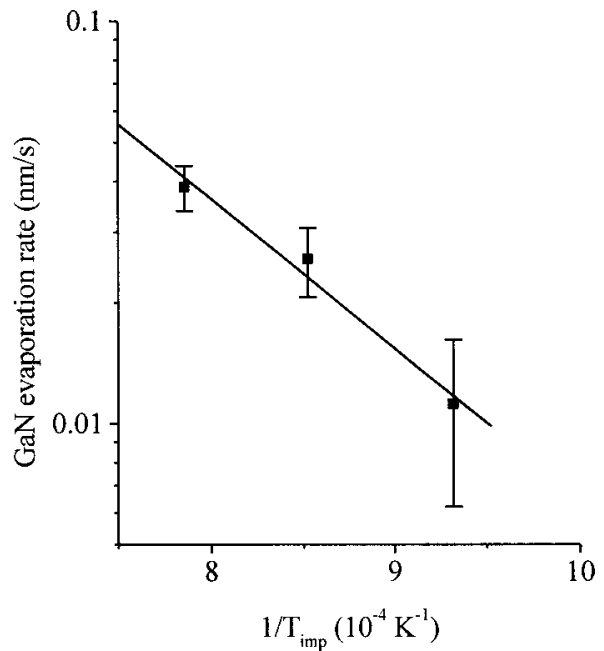

FIG. 3. Evaporation rate of $\mathrm{GaN}$ implanted with $\mathrm{Ar}^{+}$at the low dose rate as a function of inverse of the implantation temperature (squares). Solid line is the result of fitting with Eq. (2).

from the RBS/C spectra after implantation at temperature ranging from 700 to $1000^{\circ} \mathrm{C}$ and low dose rate. (For detailed analysis of the effect of implantation temperature and dose rate on damage accumulation in Ar-implanted GaN see Ref. 6.) At $T_{\text {imp }} \geqslant 800^{\circ} \mathrm{C}$ a shift of the damage peak to the surface was observed. The difference between the damage peaks at 700 and $1000^{\circ} \mathrm{C}$ was found to be $\sim 19.8 \mathrm{~nm}$. This value matches very well the shift of $\mathrm{Ar}$ maximum at $T_{\mathrm{imp}}$ $=1000^{\circ} \mathrm{C}$ obtained from the SIMS measurements. This again suggests that evaporation of thin surface layer of $\mathrm{GaN}$ took place during the bombardment at the elevated temperatures.

Lattice disorder on the surface monotonically decreased with the increase of $T_{\text {imp }}$ up to $1000^{\circ} \mathrm{C}$ (Ref. 6) and examination of the samples under scanning electron microscope showed that the surface was smooth and featureless. This means that the damage (in the Ga sublattice) was not only removed at the sample surface, but $\mathrm{Ga}$ atoms also did not accumulate at the surface and thus $\mathrm{GaN}$ evaporated congruently. It follows from the RBS/C data that measurable evaporation of $\mathrm{GaN}$ under the conditions of these experiments began at $T_{\text {imp }} \geqslant 800^{\circ} \mathrm{C}$.

The evaporation rate, $v$, was evaluated from the shift of the damage peak, $d$, as follows:

$$
v=\frac{2 \times d}{t}
$$

where $t$ is the implantation time. Figure 3 shows dependence of the evaporation rate on the inverse implantation temperature. These data are well described by the Arrhenius equation

$$
v\left(\frac{n m}{s}\right)=33.8 \times \exp \left(-\frac{0.74 \mathrm{eV}}{k T}\right) .
$$

The temperature at which the onset of GaN evaporation was observed agreed very closely with the literature data. ${ }^{7-9}$ However, the evaporation rate activation energy in our experiments was significantly lower than values reported for the thermal evaporation in vacuum $(3.6 \mathrm{eV}$ in Ref. 7, $3.93 \mathrm{eV}$ 


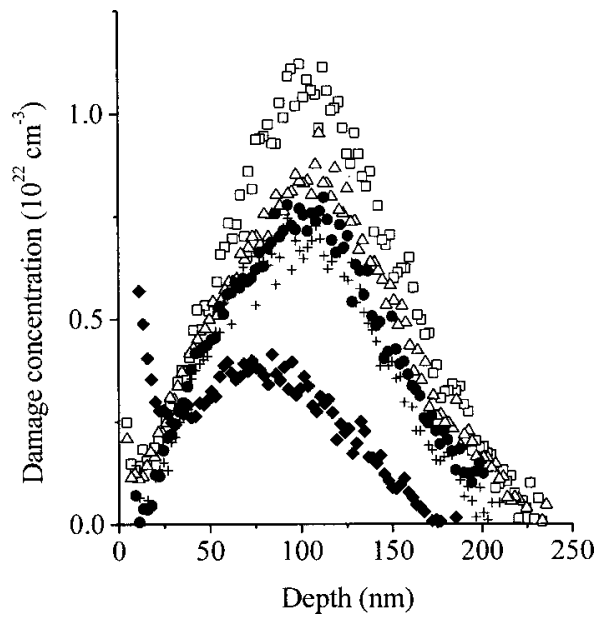

FIG. 4. Depth distribution of damage in $\mathrm{GaN}$ implanted with $\mathrm{Ar}^{+}$at the high dose rate and different temperatures: 700 (squares), 800 (triangles), 900 (circles), 1000 (crosses), and $1100{ }^{\circ} \mathrm{C}$ (diamonds).

in Ref. 8). The discrepancy could be accounted for by the radiation damage introduced by energetic $\mathrm{Ar}^{+}$ions. The ions impinging the surface brake up the chemical bonds between target atoms and displace the atoms from their lattice sites and consequently decrease the energy barrier for desorption.

Figure 4 demonstrates the damage profiles after implantation at the high dose rate and having regard to the increase of samples temperature caused by the ion beam. In the temperature range from 700 to $1000{ }^{\circ} \mathrm{C}$ there was no any noticeable shift of the damage maximum towards the surface contrary to the case when implantations were performed at the low dose rate (see Fig. 2). This indicates that the evaporation was suppressed. Since the implantation time of the samples prepared with the high dose rate was by an order shorter comparing to the samples implanted at the low dose rate the thickness of the evaporated film calculated by using Eq. (2) even at $T_{\mathrm{imp}}=1000^{\circ} \mathrm{C}$ equals only $4.1 \mathrm{~nm}$. This value is less than the depth resolution of our measurements and consequently cannot be detected.

At $T_{\text {imp }}=1100^{\circ} \mathrm{C}$ a considerable motion of the damage peak position to the surface and an increase of the damage on the surface were clearly observed (see Fig. 4). The shift of the damage peak yielded the evaporation rate of $\sim 0.6 \mathrm{~nm} / \mathrm{s}$, which is about a factor of 10 larger than the one evaluated from the Eq. (2). We believe that the increase of the surface peak height and width was most likely due to the preferential loss of nitrogen and accumulation of gallium at the surface. It was established in Ref. 10 that the evaporation rate of GaN was markedly increased by the presence of gallium metal on the surface. Thus irradiation at the high dose rate raised the sample temperature into the regime where the enhanced and incongruent evaporation of $\mathrm{GaN}$ took place.

\section{CONCLUSIONS}

In conclusion, we have shown that during high temperature ion implantation of $\mathrm{GaN}$ with $\mathrm{Ar}^{+}$radiation enhanced diffusion of implanted atoms and evaporation of thin near surface layer took place. SIMS measurements showed no redistribution of $\mathrm{Ar}$ atoms for implantation temperatures up to $700{ }^{\circ} \mathrm{C}$ and enhanced diffusion at $T_{\text {imp }}=1000^{\circ} \mathrm{C}$. Based on the shift of Ar peak and lattice damage peaks the temperature dependence of the evaporation rate of $\mathrm{GaN}$ was determined. Bombardment of $\mathrm{GaN}$ with $\mathrm{Ar}^{+}$in the temperature range from 800 to $1000{ }^{\circ} \mathrm{C}$ resulted in congruent evaporation. We have also demonstrated that decreasing the implantation time through the increase of the dose rate decreased the thickness of the evaporated layer. At $T_{\text {imp }}>1000^{\circ} \mathrm{C}$ when extra heating by the high dose rate beam was observed the evaporation of $\mathrm{GaN}$ was incongruent and significantly enhanced by accumulation of $\mathrm{Ga}$ on the surface.

${ }^{1}$ S. O. Kucheyev, J. S. Williams, and S. J. Pearton, Mater. Sci. Eng., R. 33, 51 (2001), and references therein.

${ }^{2}$ I. Usov, N. Parikh, D. Thomson, Z. Reitmeier, and R. Davis, Proceedings of the 201st Meeting of the Electrochemical Society, PV 2002-3, 198 (2002).

${ }^{3}$ X. A. Cao et al., J. Electron. Mater. 28, 261 (1999).

${ }^{4}$ S. Namba, K. Masuda, K. Gamo, A. Doi, S. Ishihara, and I. Kimura, Radiat. Eff. 6, 115 (1970).

${ }^{5}$ H. Ryssel and I. Ruge, Ion Implantation (Wiley, New York, 1986), Chap. 3.8.2.

${ }^{6}$ I. Usov, N. Parikh, D. Thomson, and R. Davis, Mater. Res. Soc. Symp. Proc. 693, I11.12.1 (2002).

${ }^{7}$ N. Grandjean, J. Massies, F. Semond, S. Yu. Karpov, and R. A. Talalaev, Appl. Phys. Lett. 74, 1854 (1999).

${ }^{8}$ O. Ambacher et al., J. Vac. Sci. Technol. B 14, 3532 (1996).

${ }^{9}$ C. B. Vartuli, S. J. Pearton, C. R. Abernathy, J. D. MacKenzie, and E. S. Lambers, J. Vac. Sci. Technol. B 14, 3523 (1996).

${ }^{10}$ R. C. Schoonmaker, A. Buhl, and J. Lemley, J. Phys. Chem. 69, 3455 (1965). 